of equal size the distribution of material serum transferrin levels at the start of the thind trimester in these groups can be compared (Table II). The coefficient of linear correlation ( $r$ ) between serum transferrin and infant size was $0.33(P<0.01)$.

TABLE II-Frequency Distribution of Maternal Serum Transferrin according to Size of the 81 Infants.

\begin{tabular}{|c|c|c|c|c|}
\hline \multirow{2}{*}{$\begin{array}{c}\text { Maternal Serum } \\
\text { Transferrin } \\
(\mathrm{mg} / 100 \mathrm{ml})\end{array}$} & \multicolumn{3}{|c|}{ Size of Infant } & \multirow[b]{2}{*}{ Total } \\
\hline & $\begin{array}{c}\text { Large } \\
(>3,240 \mathrm{~g})\end{array}$ & $\begin{array}{c}\text { Medium } \\
(2,900-3,240 \mathrm{~g})\end{array}$ & $\begin{array}{c}\text { Small } \\
(<2,900 \text { g })\end{array}$ & \\
\hline $\begin{aligned} 291-445 & \ldots \\
251-290 & \ldots \\
50-250 & \ldots\end{aligned}$ & $\begin{array}{r}13 \\
10 \\
4\end{array}$ & $\begin{array}{r}11 \\
8 \\
8\end{array}$ & $\begin{array}{l}1 \\
12 \\
14\end{array}$ & $\begin{array}{l}25 \\
30 \\
26\end{array}$ \\
\hline Total & 27 & 27 & 27 & 81 \\
\hline
\end{tabular}

- For the purpose of this calculation the infants have been rearranged into three equal groups.

$x_{i}^{2}=13.4, P<0.01 \quad$ Yates's correction applied).

\section{Discussion}

These results show that a mother's height, weight gain during pregnancy, and serum transferrin concentration are related to the weight of her infant at birth. Small infants at birth have been shown to have a higher mortality than their heavier mates (Baumgartner, 1962; Bergner and Susser, 1970). However, it is almost impossible to draw a clear line between normal and abnormal birth weights. The World Health Organization minimum normal birth weight of $2,500 \mathrm{~g}$ is probably not applicable to the group studied here (Ebrahim and D'Sa, 1966). Owing to the many factors acting on birth weight one cannot say that a birth weight of $2,600 \mathrm{~g}$ from a tall mother with malnutrition and malaria is normal simply because the weight is above the W.H.O. limit, for the infant could be otherwise subnormal. Therefore it is wiser in our opinion to classify newborn infants simply as light or heavy.

McFarlane et al. (1969), working with a Nigerian population similar to that of Tanzania, showed that the serum transferrin level was low in children suffering from protein-calorie deficiency. In our study low maternal serum transferrin was significantly related to low birth weight. We have already pointed out the prevalence of adult undernutrition in the population studied. Without dietary information we cannot go further than to suggest maternal malnutrition as a cause of low serum transferrin.
The serum albumin level was very low in some mothers and normal in others, but this did not seem to be related to the transferrin level or to infant birth weight. In children Waterlow et al. (1960) noted that individual values of serum proteins (total, albumin, and globulin) were not particularly useful in detecting malnutrition, Transferrin may therefore be a more sensitive tool in the diagnosis of malnutrition even in adults. Skinfold thicknesses and mid-arm and mid-thigh circumferences varied widely under the influence of many factors which we could not clearly define.

As pointed out by McFarlane, the serum transferrin level is easy to determine, even in the field, and the cost per person is not high. For mothers, however, more work needs to be done to study the relation of the transferrin level to nutritional status and to determine the best time for its measurement, since it rises as pregnancy advances.

This study was financed by the Tanzania Government with the help of the World Health Organization.

\section{References}

Baumgartner, L. (1962). Bulletin of the World Health Organization, 26, 175. Beilly, J. S., and Kurland, I. I. (1945). American fournal of Obstetrics and Gynecology, 50, 202

Bergner, L., and Susser, M. W. (1970). Paediatrics, 46, 946.

Burgess, L. J., Maletnlema, T. N., and Burgess, A. (1969). Tropical and Geographical Medicine, 21, 39.

Chase, H. P. (1971). In Proceedings of XIII International Congress of Paediatrics-Vienna 1971, vol. II, No. 1 Vienna, Medizinischen Akademie.

Dobbing, J. (1963). Proceedings of the Royal Society of London, Series B 159,503 .

Dobbing, J. (1970). American fournal of Diseases of Children, 120, 411.

Dobbing, J. (1971). In Proceedings of XIII International Congress of Paediatrics -Vienna 1971, vol. II, No. 1. Vienna, Medizinischen Akademie.

Ebrahim, G. J., and D'Sa, A. (1966). Fournal of Tropical Pediatrics and African Child Health, 12, 55.

Gornall, A. G., Bardawill, C. J., and David, M. M. (1949). Fournal of Biological Chemistry, 177, 751 .

Hytten, F. E., and Leitch, I. (1964). Physiology of Human Pregnancy. Oxford, Blackwell Scientific.

King, E. J., and Gilchrist, M. (1947). Lancet, 2, 201.

Klein, J (1946). American fournal of Obstetrics and Gynecology, 52, 574.

McFarlane, H., et al. (1969). Lancet, 1, 392

Maletnlema, T. N., Mhombolage, R., and Ngowi, G. E. (1972). Tanzanio Notes and Records. No. 73.

Mancini, G., Carbonara, A. O., and Heremans, J. F. (1965). Immunochemistry, 2, 235.

Stewart, R. J. C. (1971). Van den Berghs and Jurgens Nutrition Award Paper 1971.

Waterlow, J. C., Cravioto, J., and Stephen, J. M. (1960). Advances in Protein Chemistry, 15, 131 .

Zamenhof, S., van Marthens, E., and Margolis, F. L. (1968). Science, 160, 322 .

\title{
Rheumatic Fever and Rheumatic Heart Disease in Barbados: Detection and Prophylaxis
}

\author{
T. A. HASSELL， SONIA RENWICK， K. L. STUART
}

British Medical fournal, 1972, 3, 387-389

\section{Summary}

The objectives of this study were to improve our methods of secondary prophylaxis of rheumatic fever and rheumatic heart disease in Barbados, to estimate the overall

\section{Queen Elizabeth Hospital, Barbados}

T. A. HASSELL, M.B., M.R.C.P., Consultant Physician

Ministry of Health, Barbados

SONIA RENWICK, M.B., B.S., Medical Officer

University of the West Indies, Jamaica

K. L. STUART, M.D., F.R.C.P., Professor of Medicine prevalence of these diseases and the relative load imposed by them on available health services, and to measure the yield, feasibility, and efiectiveness of mass programmes for the detection and prophylactic management of rheumatic heart disease in schoolchildren.

Improved methods of surveillance and follow-up resulted in $97 \%$ adherence to therapy by patients on prophylactic penicillin. Thirty-four children, 27 with a first attack, were admitted with acute rheumatic fever, representing a $7 \%$ occupancy of children's medical beds during the 12-month period of the study. Out of a possible 3,942 schoolchildren aged 5-11 years, 3,882 (98\%) were screened for rheumatic heart disease. Four cases (about 1 per 1,000) were discovered. 


\section{Introduction}

Advances in cardiac surgery have brought benefits to many patients with rheumatic heart disease. Surgery is, however, indicated for only a small proportion of patients and in the late stages of the disease, so that the part it plays in the overall reduction of morbidity and mortality rates can be only fractional, not to mention the fact that it is still not available for the majority of persons who would benefit from it, whether in developed or in developing countries. In terms of numbers the burden of control of rheumatic fever and rheumatic heart disease will continue to rest for many years on the control of betahaemolytic streptococcal infections, on the early recognition of the rheumatic process, and on adequate prophylaxis against recurrences.

Wilson (1940) reported that $85 \%$ of patients with rheumatic fever had a recurrence within eight years of the first attack, and the frequency with which the incidence of valvular heart disease rises with each attack has been clearly shown (Biorck, 1955). It has also been shown that patients with existing rheumatic heart disease are particularly susceptible to recurrences (Spagnuolo, Pasternack, and Taranta, 1971). In addition, the changing clinical pattern of rheumatic fever (Feinstein, 1966) and the fact that many cases may be subclinical throughout their course add to the difficulties of early recognition and treatment.

No information is available on prevalence rates of rheumatic heart disease in Barbados, on the feasibility of mass programmes for its detection, or on the adequacy or effectiveness of our present methods of secondary prophylaxis. It was suspected that several patients diagnosed as having rheumatic fever or rheumatic heart disease were not continuing under medical care and were not receiving regular prophylactic treatment. For these reasons a rheumatic fever programme was started in Barbados in February 1970 with three major objectives. The first was to establish effective surveillance of known cases of rheumatic fever and rheumatic heart disease in order to improve on the current methods of secondary prophylaxis. The second was to acquire information on the overall prevalence of this disease and to assess its load on the health services of the community. The third was to measure the yield, feasibility, and effectiveness of mass programmes for the detection and prophylactic management of rheumatic heart disease in schoolchildren.

\section{Methods}

The Queen Elizabeth Hospital in Barbados has about 600 beds, 40 of which are for medical paediatric cases. It is one of the affiliated teaching hospitals of the University of the West Indies and the only general hospital in the island, which has a population of some 232,000 . It is estimated to provide treatment for more than $80 \%$ of persons requiring hospital management of either acute or subacute illnesses.

At the onset of the programme a clinic for rheumatic fever and rheumatic heart disease was established at the hospital, and the first year's experience of this clinic is analysed below. Patients are referred to this clinic by general practitioners, by other hospital physicians, and from the school screening programme. Such patients were carefully assessed at their initial visit to confirm the present or past diagnosis of rheumatic fever, which was classified as doubtful, definite, or probable according to modified Jones's criteria (Committee on Standards, 1956).

Patients with a diagnosis of definite or probable rheumatic fever were put on a prophylactic regimen of monthly injections of 1.2 megaunits of benzathine penicillin and given identification cards on which were recorded injection dates and information to practitioners on the course to be followed should the patient develop an infection or need some surgical procedure. Cards were reviewed during and at the end of the study period and the degree of adherence to the prophylactic regimen was noted. There were no untoward effects of the injections.

Apart from our assumption that single monthly injections would be a less tedious ritual than the daily taking of penicillin tablets by mouth, we think that monthly injections recorded on signed cards have the following special advantages: (a) they provide the most reliable method of determining levels of adherence to therapy and of identifying the precise time of default, and $(b)$ they remove all doubt about the actual receipt of medication.

An analysis was also made of all patients admitted to the children's wards with a diagnosis of rheumatic fever or rheumatic heart disease during the year under review. Twice-weekly visits were paid to the paediatric ward by one of us and individual patients were reviewed and assessed.

Finally, with the co-operation of the Ministry of Education, weekly visits were paid to selected primary schools and all children between the ages of 5 and 11 years on the school register, after answering a simple questionnaire, underwent cardiac auscultation by either final-year medical students or one of us. Any child with a suspicious murmur, whether this was thought to be significant or not, was referred to one of us (T.A.H.) for full clinical assessment in the rheumatic heart disease clinic.

The methods proposed by the World Health Organization for a joint co-operative protocol for the control of rheumatic fever (W.H.O., 1970) were followed as closely as possible throughout this study. This protocol after further discussion was recently adopted by a panel of W.H.O. participants as a suitable model for international co-operation in studies on the prophylaxis of rheumatic fever (W.H.O., 1972).

\section{Results}

At the end of one year 93 patients had been referred to the clinic with a diagnosis of previous rheumatic fever, of whom 61 had evidence of at least one previous definite attack of rheumatic fever. Thirty-seven of the 61 had residual chronic valvulitis, and 23 of these were aged 12 years or less (see Table).

Age and Cardiac Status of Patients with Definite Rheumatic Fever attending Rheumatic Fever Clinic

\begin{tabular}{|c|c|c|c|c|c|c|}
\hline & \multicolumn{3}{|c|}{ Age in years } & \multirow[b]{2}{*}{ Total } \\
\hline & & & $\leqslant 5$ & $6-12$ & $>12$ & \\
\hline $\begin{array}{l}\text { No residual valvulitis } \\
\text { Residual valvulitis }\end{array}$ & $\begin{array}{l}\cdots \\
\cdots\end{array}$ & 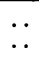 & 4 & $\begin{array}{l}16 \\
19\end{array}$ & $\begin{array}{r}4 \\
14\end{array}$ & $\begin{array}{l}24 \\
37\end{array}$ \\
\hline Total & $\ldots$ & . & 8 & 35 & 18 & 61 \\
\hline
\end{tabular}

Clinical analysis of the patients with residual valvulitis gave figures which are not unlike those reported from other parts of the world. Isolated mitral incompetence was the commonest cardiac lesion and was present in 19 patients. Combined mitral and aortic valve disease was present in 6 patients and isolated mitral stenosis in 5, while the remainder had mixed mitral disease (2), isolated aortic incompetence (3), or combined mitral incompetence and pulmonary stenosis (2).

Seventy-four patients with a definite or probable diagnosis of previous rheumatic fever were started on a regimen of monthly benzethine penicillin injections, and at the end of the study information was available on $71(96 \%)$. Three patients defaulted from the clinic and were not traced. During the year 533 injections were administered out of a possible total of 547; this represents $97 \%$ adherence to therapy by the 71 patients who continued to attend the clinic. The average number of injections received by each patient was 7.5 (S.D. 3.0). There was one relapse of rheumatic fever in this group. This occurred in one of two children who had each missed four of a possible five penicillin injections. The other developed subacute bacterial endocarditis from which he died.

There were 1,248 admissions to the medical ward of the paediatric department during the year under review, 34 of which were for either definite or probable attacks of acute rheumatic fever. The number of bed-nights due to rheumatic fever was 
$1,112(7 \%)$ out of a total of 15,695 . This represented a continuous occupancy of three beds throughout the year by patients suffering from rheumatic fever. Of the 34 admissions with a diagnosis of rheumatic fever 27 (19 definite and 8 probable) were for a first attack and 7 (6 definite and 1 probable) were for a second or subsequent attack.

Out of a total of 3,942 primary school children between the ages of 5 and 11 years attending four Government primary schools in the Bridgetown area, 3,882 (98\%) were screened. Four cases of rheumatic heart disease were detected, giving a prevalence rate of about 1 per 1,000. Three other children had previously had acute rheumatic fever but had no residual valvulitis.

\section{Discussion}

Perhaps the most important aspect of this work has been the finding that relatively unsophisticated patients and their relatives are capable of prolonged collaboration in modern prophylactic programmes against recurrences of rheumatic fever. All the patients were of Negro origin and in social classes III and IV. The overall duration of the study to date has been only one year, and no firm conclusions can be drawn until much longer follow-up has been achieved. The present level of adherence to therapy, however, clearly indicates that continued collaboration in the treatment programme may be anticipated.

The high degree of adherence to the schedule of monthly injections may be attributed to the introduction of rheumatic fever identification cards and to our success in persuading parents and patients of the importance of keeping up to date the instructions for therapy recorded on them. There are several advantages in the use of such cards. These include ease of administration of the programme, active involvement of the patient or his relative in the keeping of records of injections, and easy immediate assessment of adherence to the prophylactic regimen. Apart from removing any uncertainty about the receipt of medication, a mechanism is also provided whereby administration of injections may be decentralized to the advantage both of the overcrowded central injection department and of the patient, who may otherwise have to travel several miles simply to receive a penicillin injection. Finally, these cards also provide an inexpensive method whereby doctors, dentists, parents, and patients are constantly reminded of the need for prophylactic measures in persons who have had rheumatic fever.

Our observations suggest that rheumatic fever may account for a significant morbidity in Barbados. The data presented in this paper are largely biased towards the younger patients, so that many cases of chronic rheumatic heart disease in adults are not included. In spite of this, the occurrence of 34 admissions to the children's ward in one year for definite or probable attacks of acute rheumatic fever, 27 being first attacks, must be a source of concern, since it is well known that the hospital admission rate of patients with a given disease usually represents only a fraction of its true prevalence in the community.

The prevalence rate of rheumatic heart disease in Government primary school children aged 5-11 years was about 1 per 1,000 and was lower than we had expected though higher than that of Smith et al. (1965), who found a prevalence rate of 0.7 per 1,000 among Michigan City elementary school children. Inaccuracies have been shown in screening programmes carried out in part by medical students and non-specialist doctors (Ieri et al., 1967), and local physical conditions such as background noise, which was often present at the time of school examinations in the present study, may also militate against accurate detection of murmurs. Our findings must therefore be taken to represent minimum rates of detection for the children screened.

The high level of patient collaboration which we were able to obtain for our secondary prophylaxis programme was almost certainly the result of improved methods of surveillance and follow-up and clearly justifies further efforts to expand our campaign for the detection of previously undiagnosed cases of rheumatic heart disease. The high rate of diagnosis of new cases of rheumatic fever may also indicate a need for the initiation of programmes for primary prophylaxis against beta-haemolytic streptococcal infections in susceptible groups.

This work was supported in part by a grant from the World Health Organization. We are grateful to Dr. A. C. Graham and members of the paediatric department for their assistance and collaboration, and to Mrs. G. Mapp for secretarial help. It is a pleasure to record our thanks to the Ministry of Health, Barbados, which provided facilities for these studies, and to the Ministry of Education for their co-operation in our screening programme in schoolchildren.

\section{References}

Biorck, G. (1955). Fournal of Chronic Diseases, 1, 591. Feinstein, A. R. (1966). Bulletin on the Rheumatic Diseases, 17, 423. Ieri, A., Taranta, A., Spagnuolo, M., and Greenberg, M. (1967). fournal of
the American Medical Association, 202, 703.

Committee on Standards and Criteria for Programs of Care (1956). Circulation, 13, 617 .

Smith, J. M., et al. (1965). Circulation, 32, 966.

Spagnuolo, M., Pasternack, B., and Taranta, A. (1971). Nerv England fournal of Medicine, 285, 641.

of Medicine, 285, 641.

World $H$. alth Organization (1970). Epidemiological study and Control of Streptococcal Infections, Rheumatic Fever and Glomerulonephritis. Proposal for an International Co-nperative study. W.H.O. Internal Document CVD 70/5.

World Health Organization (1972). Programme on Rheumatic Fever Prevention: Report on a Consultation held in Cairo. W.H.O. Internal Document CVD/72.2. 